\title{
A New Method for Propagation Analysis of Earthquake Waves in Damaged Buildings: Evolutionary Normalized Input-Output Minimization (NIOM)
}

\author{
Mendbayar Oyunchimeg ${ }^{1}$ and Hideji Kawakami*2 \\ ${ }^{1}$ Graduate Student, Department of Civil and Environmental Engineering, Saitama University, Japan \\ ${ }^{2}$ Professor, Geosphere Research Institute of Saitama University, Japan
}

\begin{abstract}
We have developed a new method for wave-propagation analysis - called evolutionary normalized input output minimization (NIOM)-that models time-variant wave propagation by considering the time-variant statistical correlation between the strong motions recorded at different levels in the building. The NIOM results for actual damaged and undamaged buildings (which experienced the 1994 Northridge earthquake or the 1971 San Fernando earthquake), as well as those from an analytical elastic building model, were compared. All of these results showed two clear peaks that correspond to the incident and reflected waves propagating through the building in the vertical direction. The wave travel time was determined from these two peaks. In the case of the damaged buildings, the travel time increased during the earthquake; however, in the cases of the undamaged buildings and the elastic model, it remained almost constant during the earthquake. It was found that the change in the travel time is related to the change in the structural properties and to the degree of damage to a building. These results show that evolutionary NIOM is an effective new method for investigating the change in structural properties and the damage to buildings.
\end{abstract}

Keywords: buildings; wave propagation; wave travel time; damage

\section{Introduction}

Analyzing the behavior of a structure during an earthquake involves two problems, vibration and wave propagation, because the vibration of a structure results from seismic-wave propagation in it. Vibration methods are well known and have been developed mainly for structural engineering. In contrast, wave-propagation approaches have been mainly used to investigate ground motions due to earthquakes, and researchers use several methods (such as impulse response and correlation functions) to simplify and clarify the wave propagation in soil layers and to determine soil properties. However, a wave-propagation method can be applicable also in structural engineering, and researchers have recently contributed several works in this direction. For instance, Safak (1999), Todorovska and Lee (1989), and Todorovska et al. (2001a, 2001b) developed methods for wave-propagation analysis of the seismic response and damage in multi-story buildings.

One of the wave-propagation modeling methods-the normalized input-output minimization (NIOM) method

*Contact Author: Hideji Kawakami, Professor, Geosphere Research Institute of Saitama University, 255 Shimo-ohkubo, Saitama-shi, 338-8570 Japan

Tel: +81-48-858-3543 Fax: +81-48-858-3543

e-mail: kaw@kiban.civil.saitama-u.ac.jp

(Received November 8, 2002 ; accepted February 28, 2003)
(Kawakami and Haddadi, 1998; Haddadi and Kawakami, 1998)-is used in the present work. The NIOM method models wave propagation by considering the statistical correlation of the earthquake motions at different observation locations. We used narrow windows and developed a so-called evolutionary NIOM method for examining the time-variant properties of buildings. This method can simplify the relationships between waves observed at several levels in the building at different times from the beginning to the end of the earthquake, and it can determine the change in travel time of the wave propagating through the building. The travel time was found to be a very good indicator of damage, and its change was related to the change in the degree of damage, i.e., the change in the structural properties of the building.

\section{NIOM Method}

The normalized input-output minimization (NIOM) method can model wave propagation by considering the statistical correlation between earthquake motions observed at different points. This method can simplify the relationship between the observed waves and give arrival times, as well as their relative amplitudes, of incident and reflected waves. Since the wave-propagation velocity depends much on the characteristics of the materials through which the wave propagates, such a method is applicable not only to ground-motion analysis but also to building-record (i.e., of earthquakes) analysis. 
A brief review of the NIOM method is given below (Kawakami and Haddadi, 1998; Haddadi and Kawakami, 1998).

\subsection{NIOM method for a linear system}

When a time-invariant linear system is subjected to an earthquake motion, the input and output of the system in the frequency domain can be related by means of the transfer function $H(\omega)$. In the case of digitized earthquake motions, the output at each frequency is given by

$$
\begin{aligned}
& G\left(\omega_{i}\right)=H\left(\omega_{i}\right) F\left(\omega_{i}\right) \\
& \left(i=0, \ldots, N-1 \text { and } \omega_{i}=i \frac{2 \pi}{N \Delta t}\right),
\end{aligned}
$$

where $\Delta t$ is the sampling rate in the time domain; $N$ is the number of samples; and $F\left(\omega_{i}\right)$ and $G\left(\omega_{i}\right)$ are the Fourier transforms of the digitized earthquake input and output motions, respectively. Transfer functions depend only on the physical properties of the system. Therefore, the same transfer function as the one that defines the relationship between the observed input $F\left(\omega_{i}\right)$ and output $G\left(\omega_{i}\right)$ [Eq. (1)] should satisfy the relationship between the simplified input model $X\left(\omega_{i}\right)$ and the simplified output model $Y\left(\omega_{i}\right)$.

$$
Y\left(\omega_{i}\right)=H\left(\omega_{i}\right) X\left(\omega_{i}\right)
$$

The procedure that gives the simplified input and output models is shown schematically in Fig.1.

In the analysis of a feedback system, it should be noted that input cannot be separated from output and that the input motion in this paper is not the incident-wave motion. The motion observed at one arbitrary location (always the building's roof in this paper) is called the input motion in the following numerical analyses.

Minimizing the summation of the squared values of Fourier amplitude spectra of the input and output when a constraint is in existence (Kawakami and Haddadi, 1998; Haddadi and Kawakami, 1998) would result in a simplified input model of $X\left(\omega_{i}\right)$ and a simplified output model of $Y\left(\omega_{i}\right)$.

\subsection{NIOM method for multiple linear systems}

Controlling the contribution of high- or low-frequency components in the procedure and generalizing to multiple linear systems gives the following equation:

$$
\begin{aligned}
& X\left(\omega_{i}\right)=N \Delta \frac{\frac{1}{\left\{1+\frac{k_{0}}{c_{0}} \omega_{i}^{2}\right\}\left(c_{0}+\sum_{m=1}^{M} c_{m} \mid H_{m}\left(\omega_{i}\right)^{2}\right)}}{\sum_{n=0}^{N-1} \frac{1}{\left\{1+\frac{k_{0}}{c_{0}} \omega_{n}^{2}\right\}\left(c_{0}+\sum_{m=1}^{M} c_{m}\left|H_{m}\left(\omega_{n}\right)\right|^{2}\right\}}} \\
& Y_{l}\left(\omega_{i}\right)=N \Delta \frac{H_{l}\left(\omega_{i}\right)}{\sum_{n=0}^{N-1} \frac{k_{0}}{\left\{1+\frac{k_{0}}{c_{0}} \omega_{i}^{2}\right\}\left(c_{0}+\sum_{m=1}^{M} c_{m}\left|H_{m}\left(\omega_{i}\right)\right|^{2}\right)}}
\end{aligned}
$$

where $l=1, \ldots, M$; $M$ is the number of outputs; $c_{0}$ to $c_{M}$ are weighting constants of the squared Fourier amplitude spectra of the input and outputs, and $k_{0}$ to $k_{M}$ are those of their time derivatives. Effects of these weighting constants on the results are shown in the referred papers (Kawakami and Haddadi, 1998; Haddadi and Kawakami, 1998).

The inverse Fourier transforms of Eqs. (3) and (4) give simplified input and output models in the time domain. These simplified input and output models illustrate the statistical correlation between the observed motions, and the procedure for obtaining these models is called the NIOM method (Haddadi and Kawakami, 1998). It should be noted that the Fourier transform defined in Eq. (3) is real and symmetric with respect to the folding frequency. This means that the input model is real and symmetric with respect to time zero as in the case of auto-correlation functions.

$$
\left.\left.\begin{array}{c}
f\left(t_{i}\right) \rightarrow F\left(\omega_{i}\right) \\
\text { Observation } \\
g\left(t_{i}\right) \rightarrow G\left(\omega_{i}\right)
\end{array}\right] \rightarrow \frac{G\left(\omega_{i}\right)}{F\left(\omega_{i}\right)}=H\left(\omega_{i}\right) \rightarrow \mathbf{N I O M}\right] \rightarrow\left[\begin{array}{c}
X\left(\omega_{i}\right) \rightarrow x\left(t_{i}\right) \\
\text { Simplified model } \\
Y\left(\omega_{i}\right) \rightarrow y\left(t_{i}\right)
\end{array}\right.
$$

Fig.1. Schematic Procedure of NIOM 


\section{NIOM Analysis of Whole Length of Data}

\subsection{Elastic model of a seven-story building}

To test the method thoroughly, it was applied to an elastic analytical seven-degrees-of-freedom shear-spring model, which represents of a seven-story building. In the model, all floors have the same mass $M$ of $45.3 \mathrm{t}$ and all the stories have equal stiffness $K$ of $200 \mathrm{kN} / \mathrm{cm}$, and the fundamental period by modal analysis, $T$, is $1.43 \mathrm{~s}$. Elastic response of the model was computed by the conventional vibration method. In this calculation, the ground motion was considered as the strong motion (EW component) recorded at the ground floor of the sevenstory hotel in Van Nuys during the 1994 Northridge earthquake.

Fig. 2(a) shows the computed acceleration responses when the damping ratio in the first mode is assumed to be $10 \%$, which is the number estimated by De La Llera and Chopra (1998) for the damaged 7-story hotel in Van
Nuys. The NIOM method was used to calculate the simplified models of the computed response motions by considering the response at the roof as an input and those at the other floors as the outputs. The obtained NIOM results are shown in Fig. 2(b). Two peaks can be clearly seen in the case of the simplified output models; the left one (negative time) corresponds to the incident wave from the ground to the roof, and the right one (positive time) corresponds to the reflected wave from the roof to the ground. Incident-wave travel time from the ground floor to the roof, $\tau$, is $0.36 \mathrm{~s}$, which corresponds to the fundamental period $T=4 \tau$ of $1.44 \mathrm{~s}$, which is very similar with the period obtained by the modal analysis ( $T=1.43 \mathrm{~s})$. Note that the accuracy of the wave travel time is $0.02 \mathrm{~s}$, which can be considered as the sampling rate of the record used.
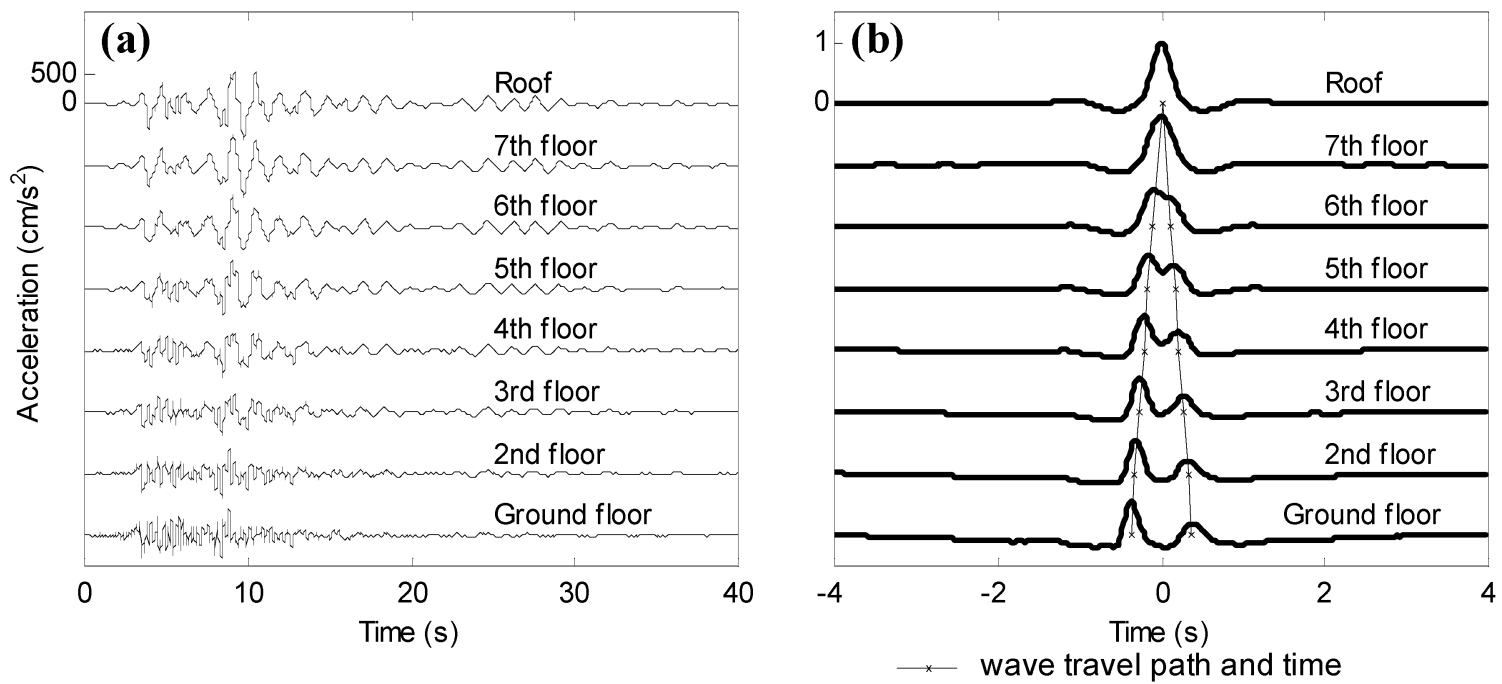

Fig.2. Analysis Results for an Elastic Seven-story Building Model: (a) Computed Acceleration Response with Damping Ratio of 10\% in First Mode; (b) Corresponding NIOM Results
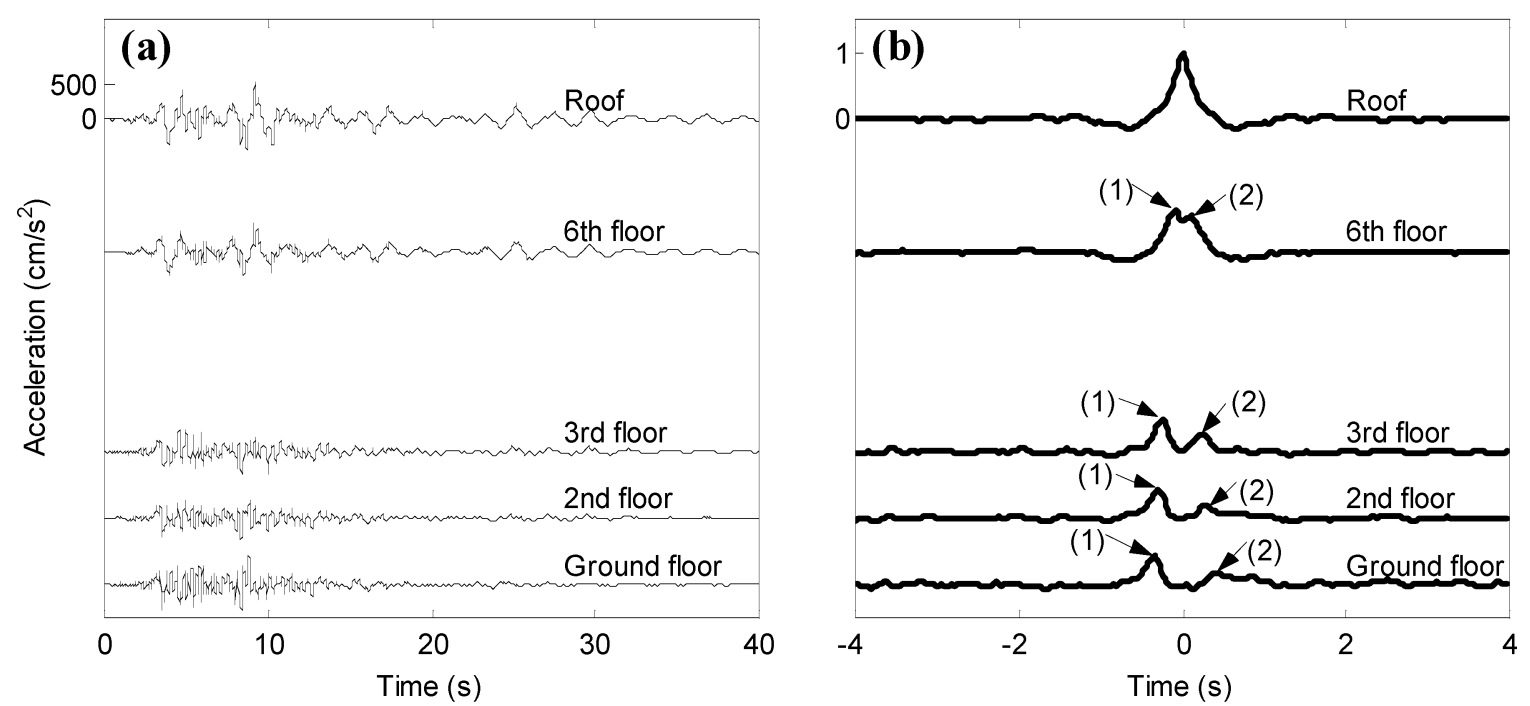

Fig.3. (a) EW Component of Strong Motions Recorded in Seven-story Hotel in Van Nuys during 1994 Northridge Earthquake; (b) Corresponding NIOM Results 


\subsection{Actual buildings}

Actual data on earthquake motions recorded in several buildings were used in this study. It includes records of the 1994 Northridge earthquake in five buildings, namely, the seven-story hotel in Van Nuys, the 20-story hotel in North Hollywood, the 13-story commercial building in Sherman Oaks, the 10-story residential building in Burbank, and a six-story office building in Los Angeles. The records of the 1971 San Fernando earthquake recorded at the Holiday Inn (on 8244 Orion Avenue) were also used. The name of this building was changed later, and this is the same building as the sevenstory hotel in Van Nuys mentioned above.

Figure 3(a) shows the EW component of the recorded strong-motion acceleration in the seven-story hotel in Van Nuys during the 1994 Northridge earthquake, and Fig. 3(b) shows the corresponding NIOM results, when the whole length of the data was used. Similarly to those shown in Fig. 2(b), the two clear peaks indicated by arrows (1) and (2) in the simplified outputs in Fig. 3(b) correspond to the incident wave from the ground to the roof and the reflected wave from the roof to the ground, respectively.

Figures 4(a)-(c) show the relationships between NS and EW components of the following three values: the maximum acceleration $A_{\max }$ at the basement/ground floor; that at the roof; and the maximum drift angle, $D_{\max } / H\left(D_{\max }\right.$ : maximum displacement at the roof; $H$ : building height). Four buildings (represented by closed symbols in Fig. 4) were reported to have suffered some damage, and the remaining two buildings (open symbols) were reported to have been undamaged (Naeim, 1997). This division between damaged and undamaged buildings is in good agreement with that indicated by the maximum drift angle shown in Fig. 4(c).

\section{Evolutionary NIOM Method}

Strong motions recorded in a damaged building, which has deformed into the plastic range, give different information from that expressed by the elastic characteristics of the building. To reveal the damage process of such a building during an earthquake, the change in building characteristics with time should be examined from the beginning to the end of the earthquake. Because the NIOM method can give simplified models of input and output motions as shown in Figs. 2 and 3, we tried to analyze the records segmentally in time and compared the results.

The observed strong motions were divided into short (but long enough to obtain reliable results) portions, and NIOM was applied to each portion. We named this method as the "evolutionary NIOM method". The shortest length of each portion was chosen to be from $2 \tau$ to $4 \tau$ ( $\tau$ is the wave travel time from the basement to the roof) so that a reliable correlation between motions at different levels in the building could be obtained. Windows with length of 5.12 to $10.24 \mathrm{~s}$, shifted by 1 or $2 \mathrm{~s}$ from the beginning to the end of the record, were used.

\section{Comparison between Evolutionary NIOM Results for Elastic Model and Damaged Seven-story Hotel in Van Nuys}

Figure 5 shows the width and central time of each narrow window used for the analysis of the elastic sevenstory-building model [Fig. 2(a)] and the seven-story hotel in Van Nuys [Fig. 3(a)]. For each of these two buildings, Figs. 6(a) and 6(b) show the evolutionary NIOM results, respectively. The lowest curve in this figure shows the output model at the ground floor when only the data from 0 to $2.56 \mathrm{~s}$ (window W-1 in Fig. 5) was used, the

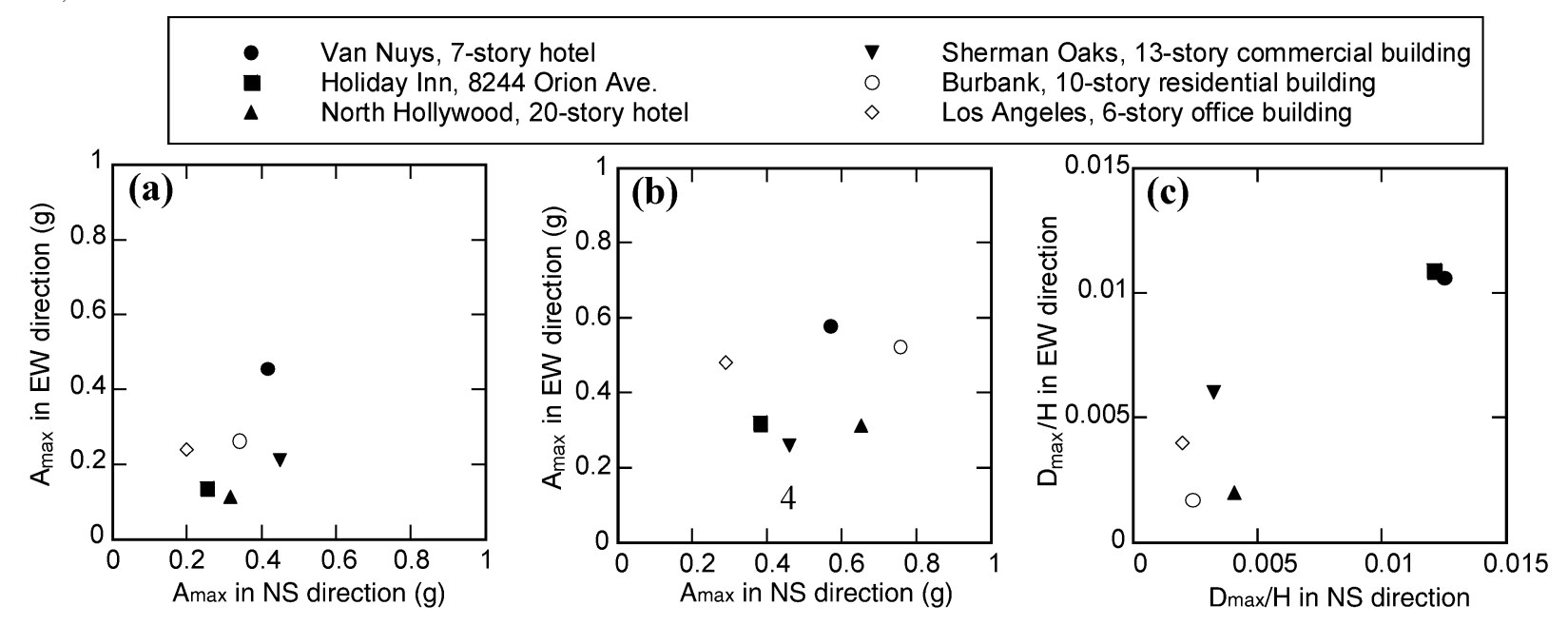

Fig.4. (a) Maximum Acceleration $\left(A_{\max }\right)$ at Basement or Ground Floor; (b) Maximum Acceleration $\left(A_{\max }\right)$ at Roof; and (c) Maximum Drift Angle ( $D_{\max } / H$, where $D_{\max }$ is maximum displacement at roof and $H$ is height of building) 


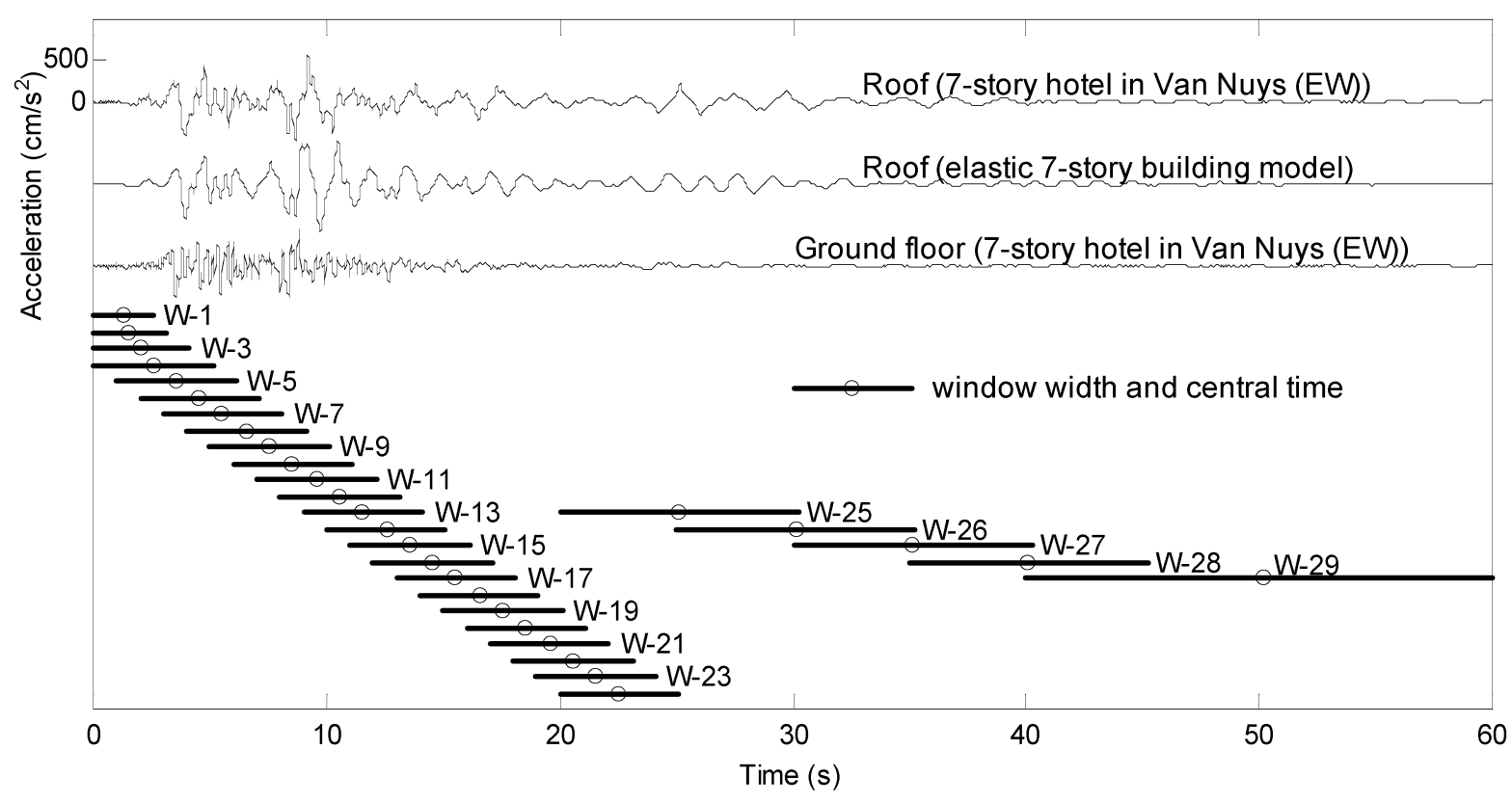

Fig.5. Narrow Windows Used in Evolutionary NIOM

second curve shows the output model when the data for 0-3.12 s (W-2) were used, and so on. The incident-wave arrival times corresponding to the peaks in negative time are shown by crosses in Fig. 6, and the arrival times when the whole data was used [0.36 s and $0.34 \mathrm{~s}$, respectively, as shown in Figs. 2(b) and 3(b)] were shown by dashed lines in Fig. 6. In the case of the elastic model, the arrival times are almost the same; however, in the case of the damaged building, the change in the arrival time is apparent, as shown in Figs. 6(a) and (b).

For these two buildings, the incident-wave arrival times obtained from Figs. 6(a) and (b) are plotted in Figs. 7 and 8 , respectively, as a function of the central time of each narrow window. For example, the incident-wave arrival time for the ground floor indicates the travel time from the ground floor to the roof. In the case of the elastic model, the arrival times are almost the same as shown in Fig. 7; however, in the case of the damaged buildings, the change in the arrival time is apparent, as shown in Fig. 8.

According to the elastic model, there should be no change, theoretically, in wave travel time during the earthquake, because the model is assumed to be elastic. Figure 7 shows the arrival times of the incident wave at several floors of the model. It clearly proves the abovementioned theory; namely, differences in the arrival times obtained between windows were only $\pm 0.02 \mathrm{~s}$, which is the same as the sampling rate.

Meanwhile, the seven-story hotel in Van Nuys located $7 \mathrm{~km}$ from the epicenter of the 1994 Northridge earthquake experienced serious structural and nonstructural damage (Naeim, 1997).

It was found that incident-wave arrival time changed from $0.24 \mathrm{~s}$ to $0.42 \mathrm{~s}$ (see Fig. 8) at the ground floor in the EW direction. In the NS direction, the arrival time changed from $0.24 \mathrm{~s}$ to $0.40 \mathrm{~s}$. As seen in Figs. 8(a) and (b), the results for the NS and EW components are similar, the first change in the incident-wave arrival time occurred at around 3-4 s, and an additional change occurred at around 7-8 s. These results indicate how the damage developed in the building during the earthquake. The possibility to locate the damage and identify the extent of damage depends on the availability of the strong motion records in the building.

\section{Other Actual Damaged Buildings \\ (1) Holiday Inn, 8244 Orion Avenue}

The building stood about $13 \mathrm{~km}$ from the epicenter of the 1971 San Fernando earthquake, and suffered minor structural damage and extensive nonstructural damage (Naeim, 1997). At that time, the building had been instrumented at three levels, namely the 1 st floor, the 4th floor, and the roof (Foutch et al., 1975). We analyzed the records of the strong motion by the NIOM method. Figure 9 shows the incident-wave arrival-time change at the 1st and 4th floors in the two horizontal directions. A significant change in the incident-wave arrival time at the $1^{\text {st }}$ and $4^{\text {th }}$ floors can be seen; in particular, at the $1^{\text {st }}$ floor, the arrival time changed from $0.16 \mathrm{~s}(t=2 \mathrm{~s})$ to $0.35 \mathrm{~s}(t=40-50 \mathrm{~s})$ in the NS direction and from $0.18 \mathrm{~s}$ to $0.35 \mathrm{~s}$ in the $\mathrm{EW}$ direction. In contrast with that in the case of the Northridge earthquake (Fig. 8), incident-wave arrival time changed gradually from the beginning to the end of the earthquake, and it shows the different progress of damage during the two different earthquakes. 

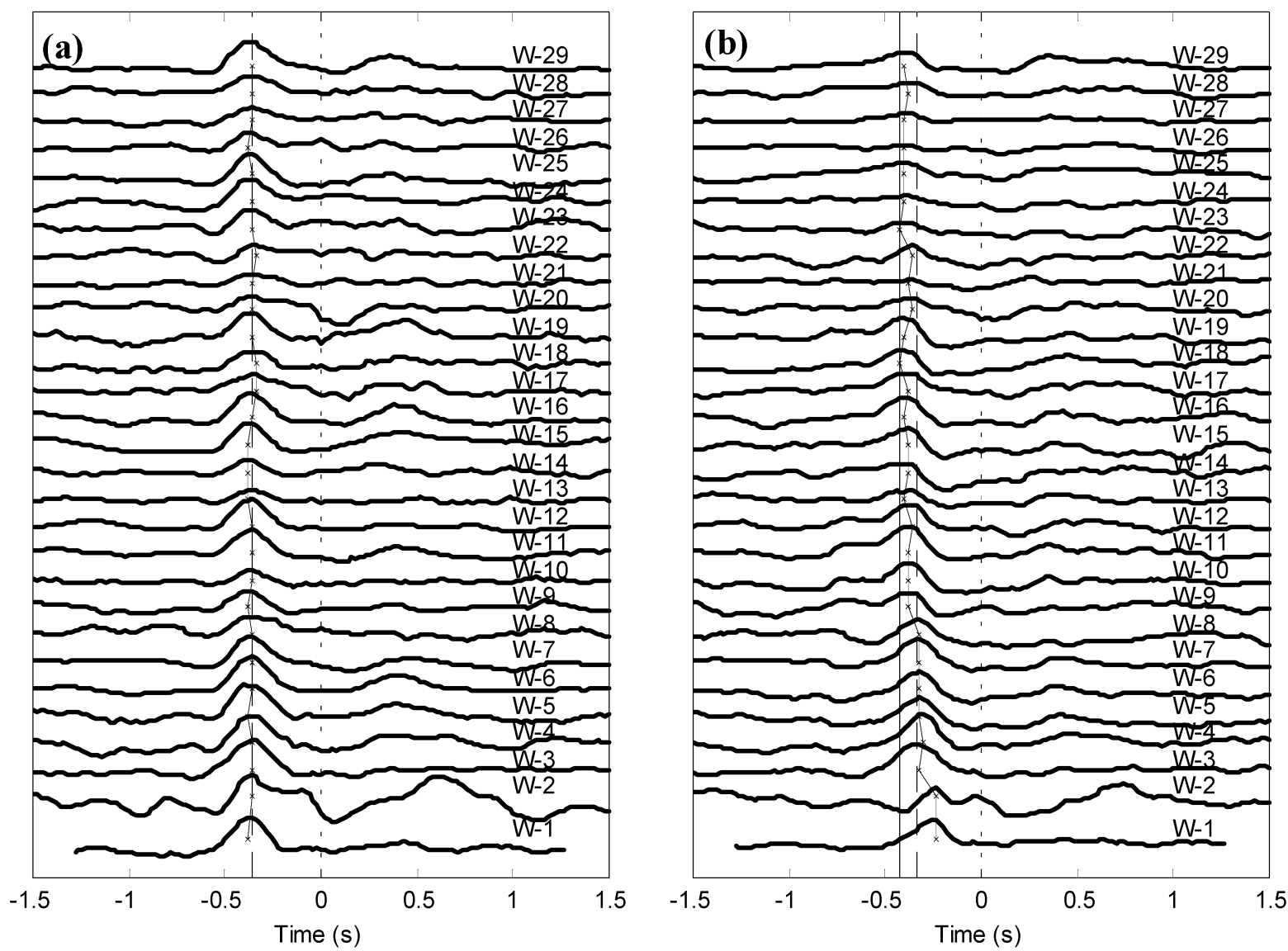

Incident wave arrival time

Maximum value of obtained incident wave arrival time

Incident wave arrival time when whole length of records is analyzed

Fig.6. Evolutionary NIOM Results When Narrow Windows Are Used: (a) Elastic 7-story Building Model, Ground Floor; and (b) 7-story Hotel in Van Nuys, Ground Floor (EW component)

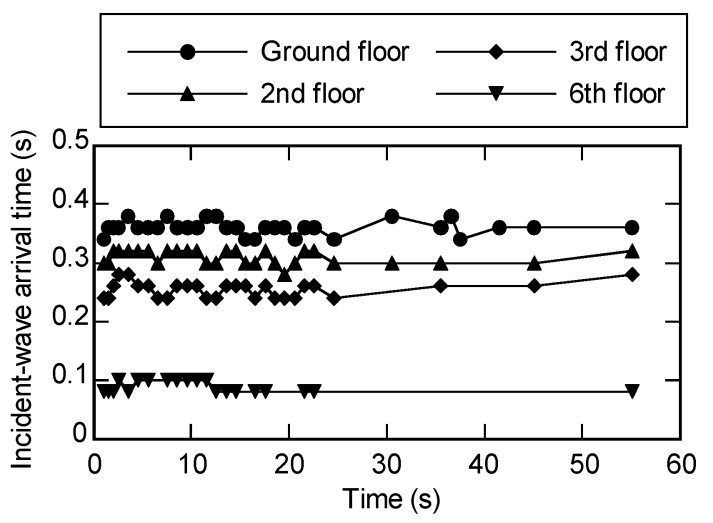

Fig.7. Incident-wave Arrival-time Change at Floors in Elastic Seven-story Building Model

\section{(2) North Hollywood, 20-story hotel}

This building was located $19 \mathrm{~km}$ from the epicenter of the 1994 Northridge earthquake and experienced heavy nonstructural and content damage (Naeim, 1997). Figure 10 shows that the incident-wave arrival time obtained in the basement changed from $0.52 \mathrm{~s}$ to $0.63 \mathrm{~s}$ in the NS direction and from $0.58 \mathrm{~s}$ to $0.66 \mathrm{~s}$ in the EW direction. This implies that the damage that occurred in the building had affected its dynamic property.

(3) Sherman Oaks, 13-story commercial building This building was $8 \mathrm{~km}$ from the epicenter during the 1994 Northridge earthquake, and it suffered some noticeable but repairable structural damage (Naeim, 1997). The incident-wave arrival time at the $2^{\text {nd }}$ sub level increased from $0.52 \mathrm{~s}$ to $0.70 \mathrm{~s}$ in the NS direction and from $0.55 \mathrm{~s}$ to $0.65 \mathrm{~s}$ in the $\mathrm{EW}$ direction during the earthquake. This change in arrival time between the $2^{\text {nd }}$ sub level and the roof is caused by the damage the building suffered.

\section{Undamaged Actual Buildings}

The 10-story residential building in Burbank and the six-story office building in Los Angeles suffered no signs of structural damage due to the 1994 Northridge earthquake (Naeim, 1997). The incident-wave arrivaltime changes at instrumented floors in these two undamaged buildings are shown in Figs. 11 and 12, respectively. Figure 11 shows that the arrival time at the 1 st floor was between $0.10 \mathrm{~s}$ to $0.12 \mathrm{~s}$ in the NS direction and between $0.08 \mathrm{~s}$ to $0.12 \mathrm{~s}$ in the EW direction, and these fluctuations are equivalent to only one or two sampling rates. In the case of the building in Los Angeles, 
Fig. 12 shows that the fluctuations are equivalent to just two or three sampling rates. It can therefore be said that almost no change in structural properties of these buildings occurred during the Northridge earthquake.

\section{Conclusion}

We developed an evolutionary method for normalized input-output minimization (NIOM). It enables timevariant wave propagation modeling by taking into account the time-variant statistical correlation among the strong motions recorded at different levels in a building. The NIOM results for actual damaged and undamaged buildings, as well as those from an analytical elastic building model, were compared. In the case of the damaged buildings, for which large maximum drift angles were also observed, the travel time increased during the earthquake; however, in the cases of the undamaged buildings and the elastic model, it remained almost constant during the earthquake. It was found that the change in the travel time is related to the change in the structural properties and to the degree of damage to a building. These results show that evolutionary NIOM is an effective new method for investigating the change in structural properties and the damage to buildings. This method has an advantage of investigating building behavior during earthquakes without assuming any structural properties, because only strong motion time histories recorded in the building are needed.
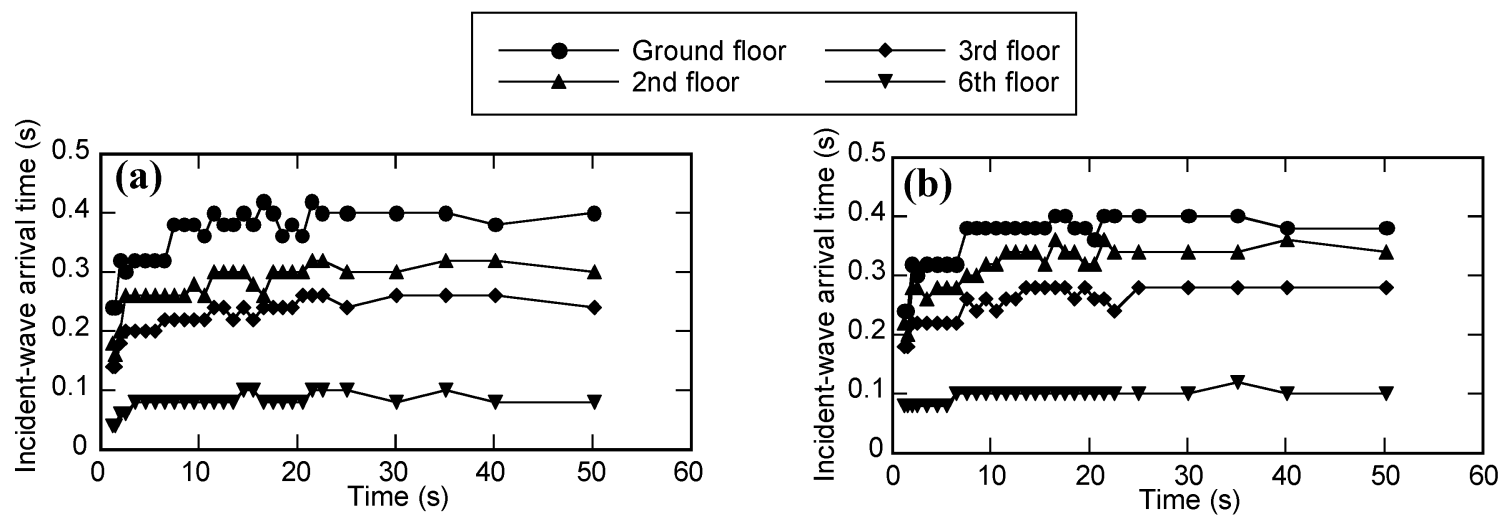

Fig.8. Incident-wave Arrival-time Change at Instrumented Floors in Damaged 7-story Hotel in Van Nuys: (a) NS Direction and (b) EW Direction
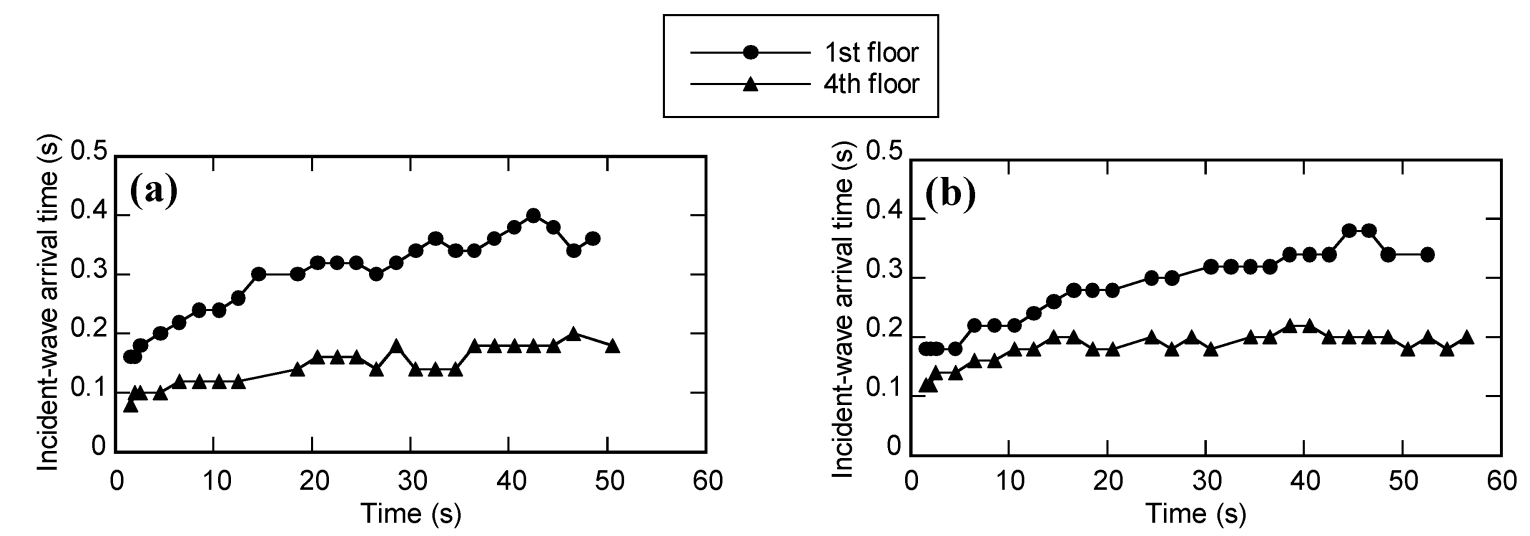

Fig.9. Incident-wave Arrival-time Change at Instrumented Floors in Damaged Holiday Inn Building (8244 Orion): (a) NS Direction and (b) EW Direction
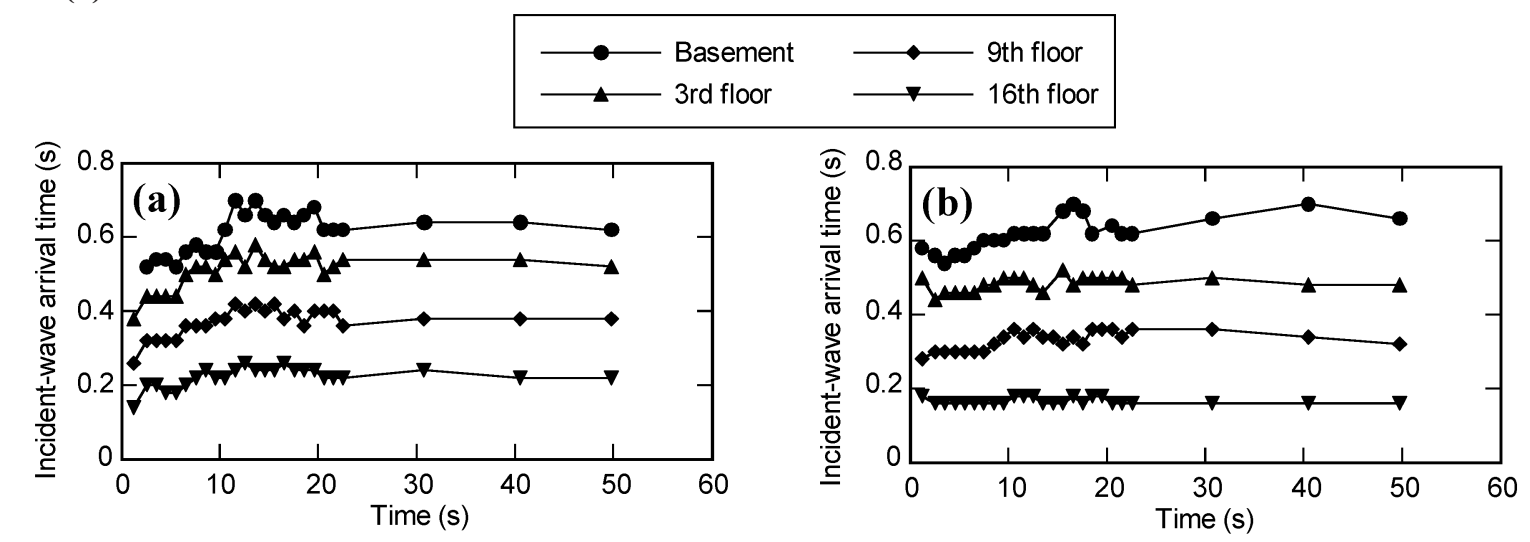

Fig.10. Incident-wave Arrival-time Change at Instrumented Floors in Damaged 20-story Hotel in North Hollywood: (a) NS Direction and (b) EW Direction 

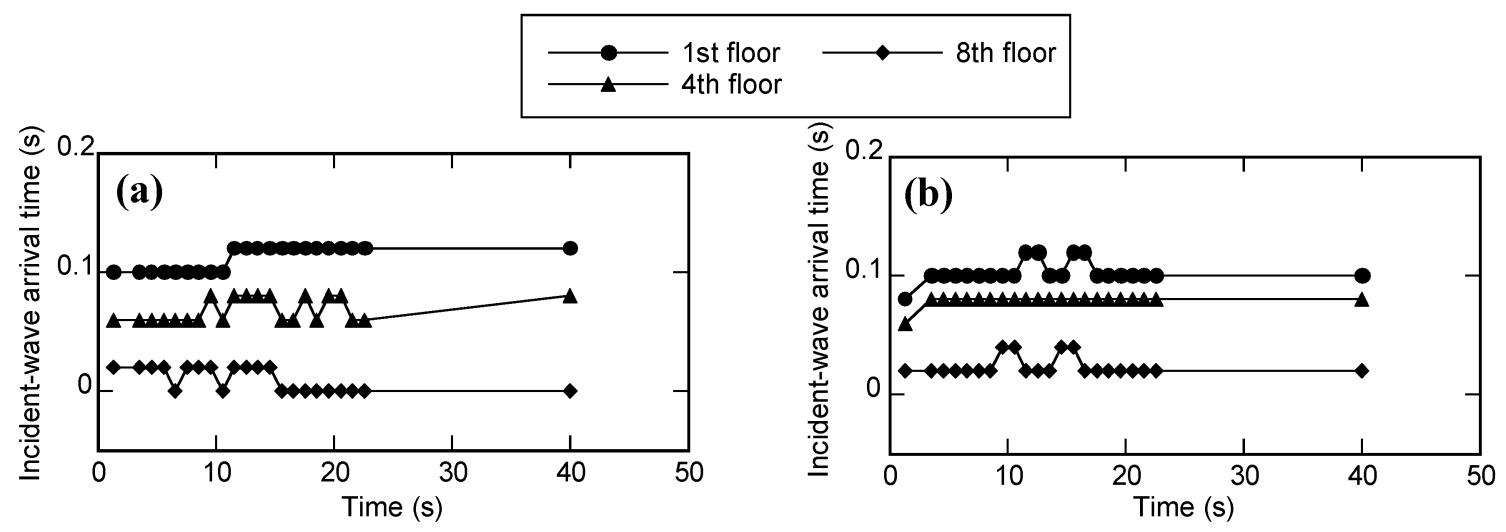

Fig.11. Incident-wave Arrival-time Change at Instrumented Floors in Undamaged 10-story Residential Building in Burbank: (a) NS Direction and (b) EW Direction

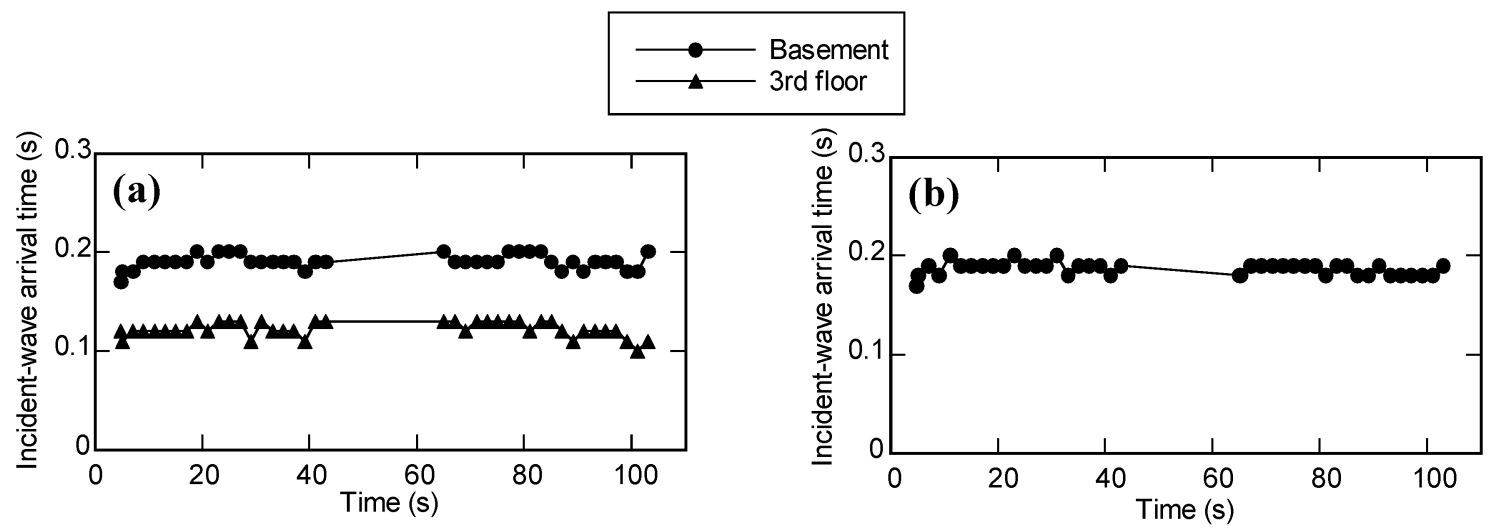

Fig.12. Incident-wave Arrival-time Change at Instrumented Floors in Undamaged Six-story Office Building in Los Angeles: (a) NS Direction and (b) EW Direction

\section{Acknowledgments}

We are grateful to the National Geophysical Data Center, Colorado, and Strong-motion Instrumentation Program, California Department of Conservation, Division of Mines and Geology of the USA, for providing the earthquake strong-motion records used in our study.

\section{References}

1) California Strong Motion Instrumentation Program (CSMIP) (1994). Processed data from the Northridge Earthquake of 17 January 1994. Report OSMS 94-11, California

2) De La Llera, J.C. and Chopra, A.K. (1998). Evaluation of seismic code provisions using strong-motion building records from the 1994 Northridge earthquake. Report No. UCB/EERC-97/16, Earthquake Engineering Research Center, University of California at Berkeley

3) Foutch, D.A. et al. (1975). Dynamic responses of six multistory buildings during the San Fernando earthquake. Report no. EERL 75-02, California Institute of Technology, Pasadena, California

4) Haddadi, H. R. and Kawakami, H. (1998). Modeling wave propagation by using normalized input-output minimization (NIOM) method for multiple linear systems. Journal of Structural Mechanics and Earthquake Engineering, JSCE, 584/I-42, PP.29-
39.

5) Kawakami, H. and Haddadi, H.R. (1998). Modeling wave propagation by using normalized input output minimization (NIOM). Soil Dynamics and Earthquake Engineering, 17, PP.117126.

6) Naeim, F. (1997). Performance of extensively instrumented buildings during the January 17, 1994 Northridge earthquake. Los Angeles: John A. Martin \& Associates, JAMA report number $97-$ 7530.68

7) National Geophysical Data Center (1996). Earthquake strong motion 3-volume CD-ROM collection. Boulder, Colorado

8) Safak, E. (1999). Wave-propagation formulation of seismic response of multistory buildings. Journal of Structural Engineering, 125(4), PP.426-437.

9) Todorovska, M.I. and Lee, V.W. (1989). Seismic waves in buildings with shear walls or central core. Journal of Engineering Mechanics, 115(12), PP.2669-2686.

10) Todorovska, M.I., Ivanovic, S.S. and Trifunac, M.D. (2001a). Wave propagation in a seven-story reinforced concrete building, I. Theoretical models. Soil Dynamics and Earthquake Engineering, 21, PP.211-223.

11) Todorovska, M.I., Ivanovic, S.S. and Trifunac, M.D. (2001b). Wave propagation in a seven-story reinforced concrete building, II. Observed wave numbers. Soil Dynamics and Earthquake Engineering, 21, PP.225-236. 